\title{
Connectional Modularity of Top-Down and Bottom-Up Multimodal Inputs to the Lateral Cortex of the Mouse Inferior Colliculus
}

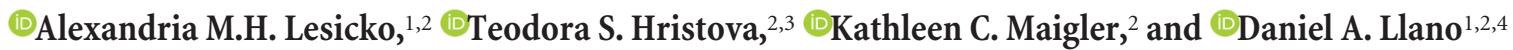 \\ ${ }^{1}$ Neuroscience Program, ${ }^{2}$ Beckman Institute, ${ }^{3}$ College of Veterinary Medicine, and ${ }^{4}$ Department of Molecular and Integrative Physiology, University of \\ Illinois at Urbana-Champaign, Urbana, Illinois 61801
}

The lateral cortex of the inferior colliculus receives information from both auditory and somatosensory structures and is thought to play a role in multisensory integration. Previous studies in the rat have shown that this nucleus contains a series of distinct anatomical modules that stain for GAD-67 as well as other neurochemical markers. In the present study, we sought to better characterize these modules in the mouse inferior colliculus and determine whether the connectivity of other neural structures with the lateral cortex is spatially related to the distribution of these neurochemical modules. Staining for GAD-67 and other markers revealed a single modular network throughout the rostrocaudal extent of the mouse lateral cortex. Somatosensory inputs from the somatosensory cortex and dorsal column nuclei were found to terminate almost exclusively within these modular zones. However, projections from the auditory cortex and central nucleus of the inferior colliculus formed patches that interdigitate with the GAD-67-positive modules. These results suggest that the lateral cortex of the mouse inferior colliculus exhibits connectional as well as neurochemical modularity and may contain multiple segregated processing streams. This finding is discussed in the context of other brain structures in which neuroanatomical and connectional modularity have functional consequences.

Key words: auditory; GAD; midbrain; module; multisensory; tract tracing

\section{Significance Statement}

Many brain regions contain subnuclear microarchitectures, such as the matrix-striosome organization of the basal ganglia or the patch-interpatch organization of the visual cortex, that shed light on circuit complexities. In the present study, we demonstrate the presence of one such micro-organization in the rodent inferior colliculus. While this structure is typically viewed as an auditory integration center, its lateral cortex appears to be involved in multisensory operations and receives input from somatosensory brain regions. We show here that the lateral cortex can be further subdivided into multiple processing streams: modular regions, which are targeted by somatosensory inputs, and extramodular zones that receive auditory information.

\section{Introduction}

The inferior colliculus (IC) is classically viewed as an integration center for ascending auditory information. While this role may be accurately ascribed to the central nucleus of the IC (CNIC), the lateral cortex (LC) likely performs a distinct function, as evi-

\footnotetext{
Received Nov. 15, 2015; revised Sept. 1, 2016; accepted Sept. 4, 2016.

Author contributions: A.M.H.L. and D.A.L. designed research; A.M.H.L., T.S.H., and K.C.M. performed research; A.M.H.L., T.S.H., and K.C.M. analyzed data; A.M.H.L. and D.A.L. wrote the paper.

This work was supported by National Science Foundation Integrative Graduate Education and Research Traineeship Fellowship 0903622 (A.L.); a summer traineeship from the Office of the Director, National Institutes of Health (T35 OD011145; T.H.); and National Institutes of Health-National Institute on Deafness and Other Communication Disorders Grant DC013073. We thank Kevin Stebbings for many useful discussions on this topic, and would like to acknowledge Melissa Farley for her artistic input on the final figure.

Correspondence should be addressed to Daniel A. Llano, 2355 Beckman Institute, University of Illinois at UrbanaChampaign, 405 North Mathews Avenue, Urbana, IL 61801. E-mail: d-Ilano@illinois.edu.

DOI:10.1523/JNEUROSCI.4134-15.2016

Copyright $\odot 2016$ the authors $\quad 0270-6474 / 16 / 3611037-14 \$ 15.00 / 0$
}

denced by its multimodal connectivity (Tokunaga et al., 1983; Coleman and Clerici, 1987). The major ascending inputs to the LC arise from somatosensory brainstem nuclei, including the dorsal column nuclei and spinal trigeminal nucleus, and from other subdivisions within the IC (Jane and Schroeder, 1971; Schroeder and Jane, 1971, 1976; RoBards et al., 1976; Hand and Van Winkle, 1977; Willard and Martin, 1983; Björkeland and Boivie, 1984; Paloff and Usunoff, 1991; Li and Mizuno, 1997). The LC also receives top-down information from the superior colliculus (SC) and the somatosensory, auditory, and visual cortices (Cooper and Young, 1976; Robards, 1979; Adams, 1980; Faye-Lund, 1985; Winer et al., 1998). Previous studies that have mapped the terminal distributions of these pathways show that many of them form discontinuous patches within the LC in a number of species, including the mouse, guinea pig, cat, and monkey (Wise and Jones, 1977; Wiberg and Blomqvist, 1984; Faye-Lund and Osen, 

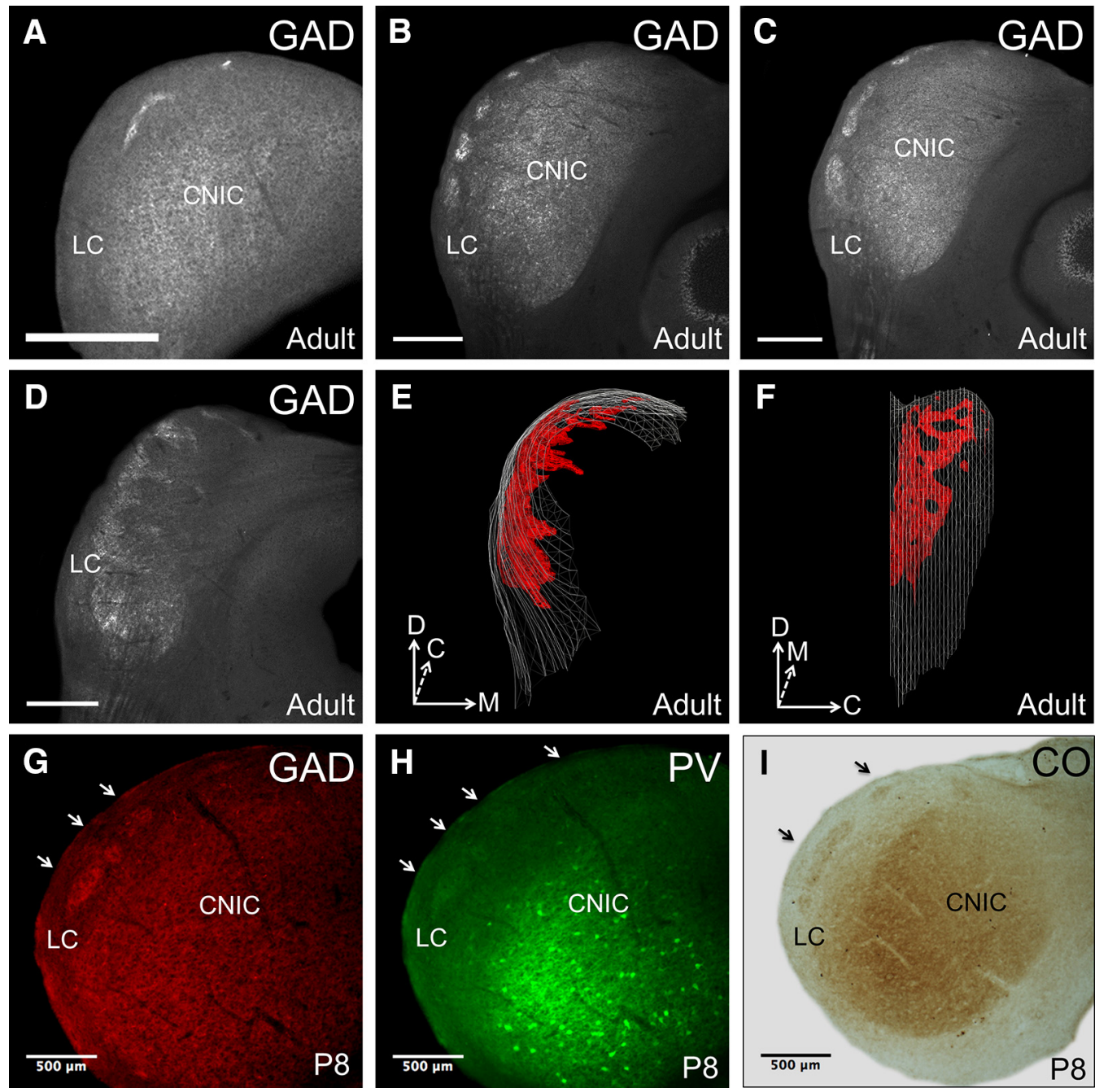

Figure 1. Neurochemical modules in the mouse IC. $A, G A D-67$ immunostaining in a caudal section of the $L C$, showing the presence of modules. $B$, GAD-67 immunostaining in a midrostrocaudal section, demonstrating the presence of discrete modules in the LC. C, GAD-67 immunostaining in a section adjacent to that in $\boldsymbol{B}$, showing the fusion of discrete modules. D, GAD-67 immunostaining in a rostral section of the $L C$, showing the medial curving of the modules. $\boldsymbol{E}$, Three-dimensional reconstruction of GAD-67 modules in the $L C$ of an adult mouse (rostral view). $\boldsymbol{F}$, Lateral view of reconstruction. Note the lattice-like pattern formed by alternating areas of stained and unstained tissue. G, GAD-67 staining on a section from a P8 mouse. Arrows indicate the locations of modules. $\boldsymbol{H}$, PV staining on an adjacent section from a P8 mouse. I, CO staining on an adjacent section from a P8 mouse. D, Dorsal; $M$, medial; C, caudal. Scale bars: A-D, $500 \mu \mathrm{m}$.

1985; Wiberg et al., 1987; Saldaña and Merchań, 1992; Saldaña et al., 1996; Zhou and Shore, 2006; Stebbings et al., 2014).

In the rat, the LC contains an additional level of compartmental organization that distinguishes it from the CNIC: layer 2 of the LC contains a network of modules that stain positively for a number of neurochemical and metabolic markers, including glutamic acid decarboxylase-67 (GAD-67), acetylcholinesterase (AChE), parvalbumin (PV), nicotinamide adenine dinucleotide phosphatediaphorase (NADPH-d), and cytochrome oxidase (CO) (Mugnaini and Oertel, 1985; Chernock et al., 2004; Ito et al., 2009; Choy Buentello et al., 2015). Though the functional significance of these modules remains unknown, their spatial distribution bears striking resemblance to the clusters of terminals formed by sensory inputs to the LC (Huffman and Henson, 1990; Cramer and Gabriele, 2014).

Though Chernock et al. (2004) have suggested that these modules are unique to the rat IC, they are clearly visible in mouse tissue stained for GAD-67, NADPH-d, AChE, and CO (Gonzalez-Lima and Cada, 1994; Paxinos and Franklin, 2004; Ono et al., 2005; Stebbings et al., 2014; Choy Buentello et al., 2015). In the present study, we sought to confirm the presence of these neurochemical modules in the mouse IC and to determine whether each marker stains the same set of modules or whether multiple modular networks exist within the LC. Using tracttracing and immunohistochemical approaches, we also investigated whether the termination patterns of top-down and bottom-up auditory and somatosensory inputs correlate with this underlying modular organization.

\section{Materials and Methods}

Animals. Experiments were performed in adult BALB/c mice of both sexes unless noted otherwise. All procedures were approved by the Institutional Animal Care and Use Committee at the University of Illinois. Animals were housed in care facilities approved by the American Association for Assessment and Accreditation of Laboratory Animal Care. Every attempt was made to minimize the number of animals used and to reduce suffering at all stages of the study.

Tracer injection. Mice were anesthetized intraperitoneally with a mixture of ketamine hydrochloride $(100 \mathrm{mg} / \mathrm{kg})$ and xylazine $(3 \mathrm{mg} / \mathrm{kg})$ and a small hole was drilled in the skull above the structure of interest. A glass micropipette (tip diameter, $20-30 \mu \mathrm{m}$ ) was filled with either a $5 \%$ solution of 3000 molecular weight biotinylated dextran amine (BDA) in PBS, pH 7.4, or AAV5-CaMKIIa-hChR2(H134R)-mCherry construct (AAV5) and lowered into the brain. The lower molecular weight form of 

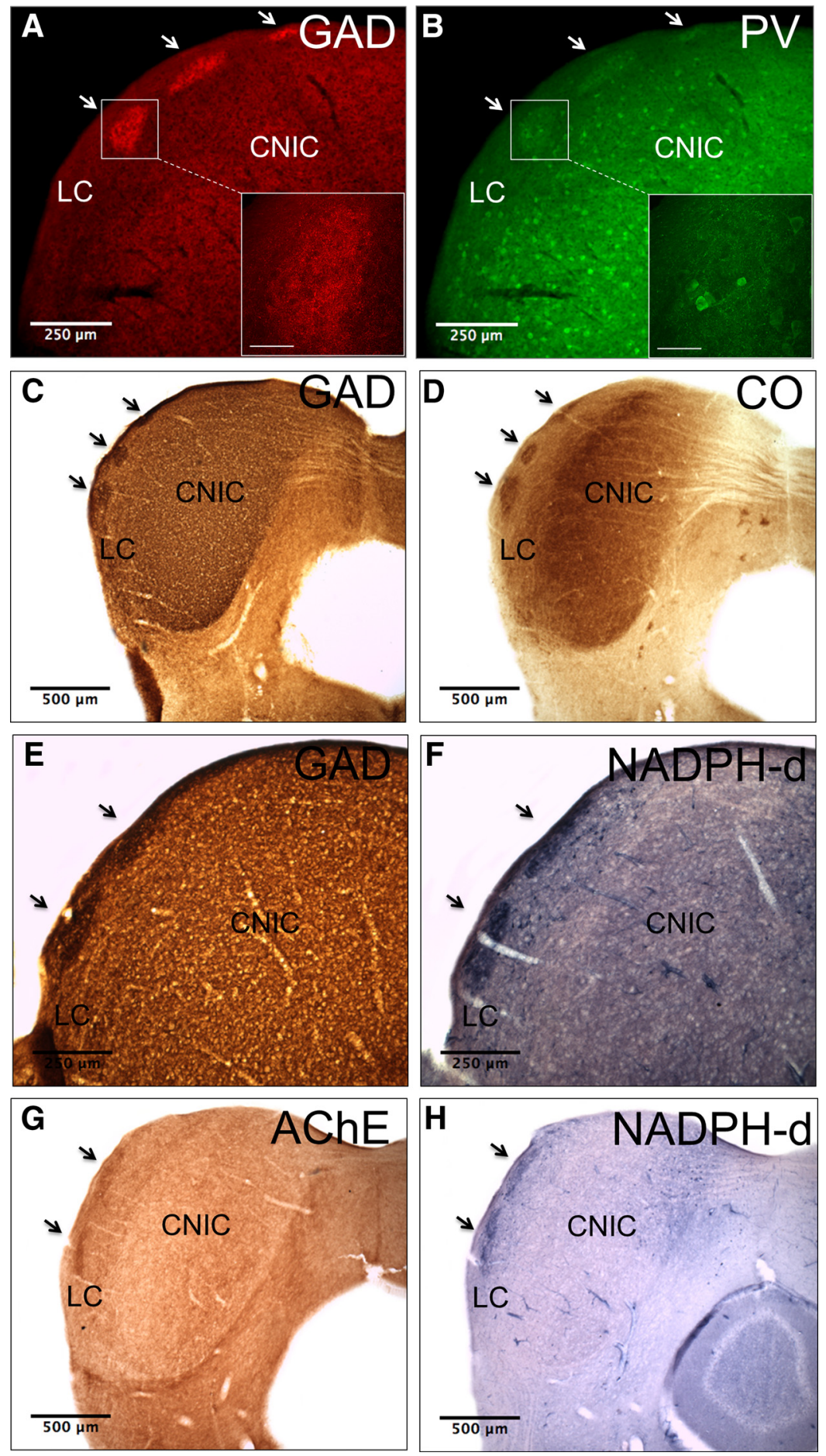

Figure 2. Markers stain a single network of neurochemical modules. A, GAD-67 immunostaining in tissue from an adult mouse. Arrows indicate the locations of modules. Inset, High-power image of GAD-67 labeling in the ROI. Note the high density of GAD-67-positive puncta. $\boldsymbol{B}$, PV immunostaining on the same section as in $\boldsymbol{A}$. Note that PV modules colocalize with GAD-67 modules. Inset, High-power image of PV labeling in the ROI. Note labeled cells and modular neuropil. C, GAD-67 immunostaining in tissue from an adult mouse. $D, C O$ staining in a section adjacent to that in C. E, GAD-67 immunostaining in tissue from an adult mouse. $F$, NADPH-d staining in a section adjacent to that in $E$. G, AChE staining in tissue from an adult mouse. $\boldsymbol{H}, \mathrm{NADPH}$-d staining in a section adjacent to that in $\mathbf{G}$. Scale bar in insets $=50 \mu \mathrm{m}$.

BDA was chosen as it has proven to be a superior anterograde tracer in our hands and others (Ling et al., 2012). For subcortical injections, BDA was injected iontophoretically using $5 \mu \mathrm{A}$ positive current pulses $(50 \%$ duty cycle) for 10-20 min. A $15 \mu \mathrm{A}$ negative holding current was applied during placement and removal of the pipette to prevent unwanted leakage of the tracer. For cortical injections (unless otherwise noted), 50-80 $\mathrm{nl}$ of BDA or the AAV5 construct was pressure injected using a WPI Nanoliter 2010 injector and Micro4 pump controller.

Tissue processing. Following a 3-7 d survival period, animals were anesthetized with pentobarbital $(100 \mathrm{mg} / \mathrm{kg})$ and perfused transcardially with $4 \%$ paraformaldehyde (PFA) in PBS. Brains were removed and postfixed overnight in the PFA solution. After being cryoprotected in an ascending series of sucrose solutions, each brain was embedded and cut into 40$\mu \mathrm{m}$-thick sections on a freezing sledge microtome. For tissue containing BDA, the sections were transferred to a solution containing Alexa Fluor 488-conjugated streptavidin (catalog \#S-11223, Invitrogen) to visualize the BDA injection sites and regions of label in the LC.

Immunostaining. Sections were microwaved for $15 \mathrm{~s}$ and then incubated for $30 \mathrm{~min}$ in a solution of $0.3 \%$ Triton X-100 in PBS to enhance membrane permeability. The sections were then transferred to a blocking solution consisting of $0.3 \%$ Triton X-100 and $3 \%$ goat serum in PBS and incubated for $30 \mathrm{~min}$. The primary antibody solution consisted of 1:1000 mouse anti-GAD-67 monoclonal antibody (catalog \#MAB5406, Millipore) or 1:1000 rabbit anti-PV polyclonal (PV 25, Swant) in the blocking solution. Sections were incubated in this solution overnight and rinsed in three changes of the Triton X-100 solution the following day. The sections were then transferred to a secondary antibody solution and incubated at room temperature for $2 \mathrm{~h}$. This solution consisted of either 1:100 Alexa Fluor 568-conjugated goat anti-mouse secondary antibody (for GAD-67, catalog \#A-11004, Invitrogen) or 1:100 Alexa Fluor 568-conjugated goat anti-rabbit secondary antibody (for PV, catalog \#A-11008, Invitrogen). Following a final series of washes in PBS, the sections were mounted on gelatin-coated slides and coverslipped with an anti-fade solution (Vectashield; Vector Laboratories).

Histochemistry. The Scherer-Singler et al. (1983) method for NADPH-d staining was used with minor modifications. Free-floating sections were incubated in a solution containing 15 mM sodium malate (catalog \#M1125, Sigma), 1 mm NADP (catalog \#N1630, Sigma), and $1 \mathrm{~mm}$ nitro blue tetrazolium (catalog \#N6876, Sigma) in 0.1 м Tris-HCl, pH 8.0, for $1 \mathrm{~h}$ at $37^{\circ} \mathrm{C}$. The sections were then rinsed in three washes of PBS and mounted on gelatincoated slides. For AChE staining, acetylthiocholine iodide (catalog \#A5751, Sigma) was added to maleate buffer, $\mathrm{pH} 6.0$, and the following were added in order: $0.1 \mathrm{M}$ sodium citrate dihydrate (catalog \#W302600, Sigma), 30 $\mathrm{mm}$ copper (II) sulfate (catalog \#451657, Sigma), water, and $5 \mathrm{~mm}$ potassium ferricyanide (catalog \#702587, Sigma; Karnovsky and Roots, 1964). Following a $2 \mathrm{~h}$ incubation period at room temperature, the sections were removed and rinsed in three washes of PBS. For cytochrome oxidase staining, tissue sections were incubated in the dark at $37^{\circ} \mathrm{C}$ in a solution containing $50 \mathrm{mg}$ of DAB (catalog \#D8001, Sigma), $25 \mathrm{mg}$ of cytochrome C (catalog \#C2037, Sigma), and $4 \mathrm{~g}$ of sucrose in $90 \mathrm{ml} 0.1 \mathrm{M}$ PBS, pH 7.4 (Wong-Riley, 1979). Sections were removed from the solution when a dark 


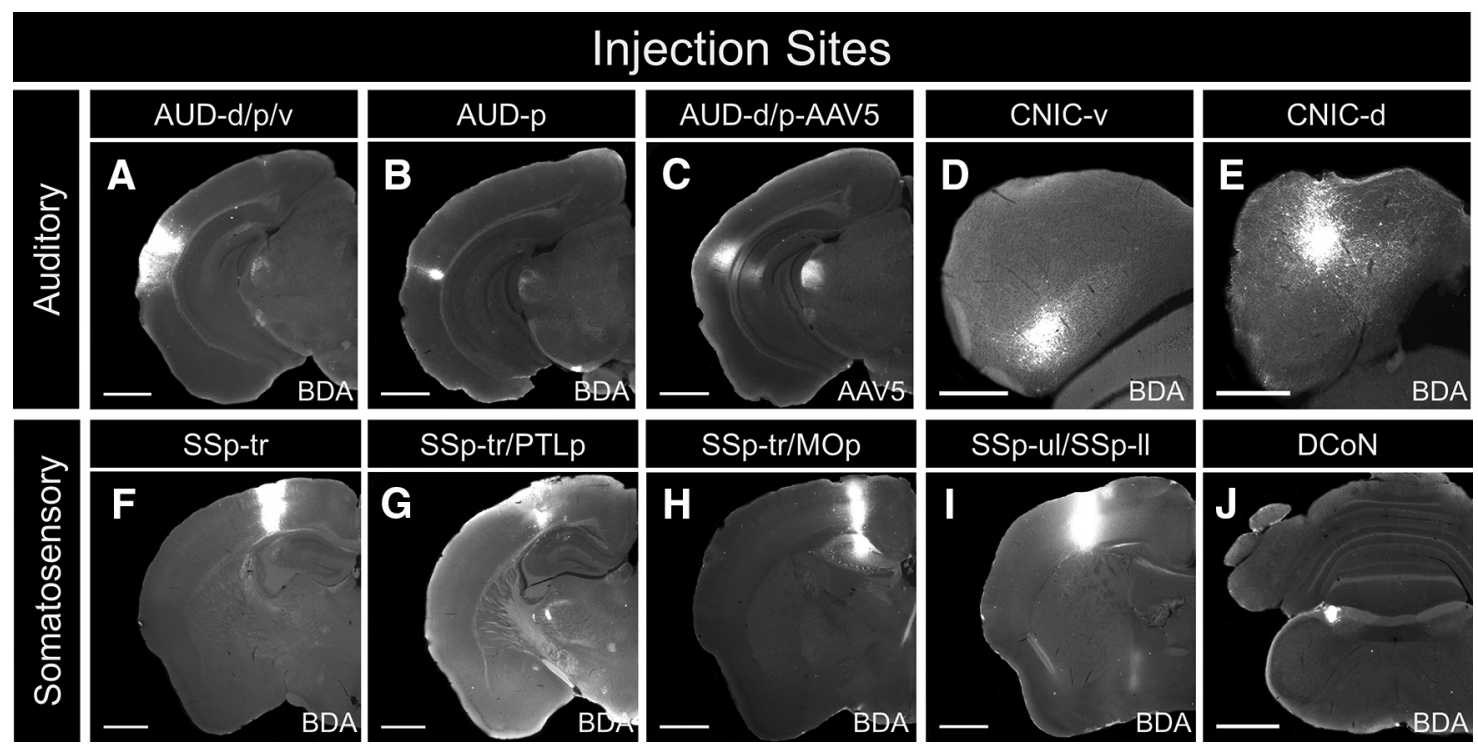

Figure 3. Injection sites for connectional studies. $A$, Pressure injection of BDA into the dorsal, primary, and ventral regions of the auditory cortex (AUD-d/p/v). $B$, Iontophoretic injection of BDA into the primary region of the auditory cortex (AUD-p). C, Pressure injection of AAV 5 into the dorsal and primary regions of the auditory cortex (AUD-d/p-AAV5). D, Iontophoretic injection of BDA into the ventral portion of the CNIC (CNIC-v). $E$, lontophoretic injection of BDA into the dorsal portion of the CNIC (CNIC-d). $F$, Pressure injection of BDA into the trunk region of the somatosensory cortex (SSp-tr). G, Pressure injection of BDA into the trunk region of the somatosensory cortex and the posterior parietal association areas (SSp-tr/PTLp). $\boldsymbol{H}$, Pressure injection of BDA into the trunk region of the somatosensory cortex and the primary motor areas (SSp-tr/MOp). I, Pressure injection of BDA into the upper limb and lower limb regions of the primary somatosensory cortex(SSp-ul/SSp-II). $J$, Iontophoretic injection of BDA into the dorsal column nuclei (DCoN). Scale bars: $A-C, F-J, 1000 \mu \mathrm{m} ; \boldsymbol{D}, \boldsymbol{E}, 500 \mu \mathrm{m}$.

brown reaction product was visible and were washed in three changes of the PBS solution. For all three staining procedures, mounted sections were dehydrated in a series of alcohol baths, defatted with Histo-Clear, and coverslipped with Permount (catalog \#S70104, Thermo Fisher Scientific).

Imaging and analysis. Sections used for histochemical analysis were imaged using an Olympus IX70 microscope and QImaging software. Tissue used in connectional studies was imaged with a Leica SP8 laser scanning confocal microscope and LAS X control software. For each IC tissue section containing anterograde label, $20 \times$ mosaic $Z$-stacks were taken throughout the entire depth and $x-y$ plane of the IC. The stacks were collapsed into $2 \mathrm{D}$ maximum intensity projections and tiled into a single image using LAS X software. Photoshop was used to adjust the color balance and to draw masks around the edge of the tissue to cover the embedding medium. Reconstructions were performed using Neurolucida software. The Allen Reference Atlas was used to determine the location of injection sites and the approximate rostrocaudal coordinates of IC tissue sections (Goldowitz, 2010).

\section{Results}

The LC of the mouse IC contains neurochemical modules Immunostaining for GAD-67 in coronal sections revealed densely stained, discontinuous clusters of GAD-67 labeling throughout nearly the entire rostrocaudal extent of the LC (Fig. $1 A-D)$. Modules first appear in the caudal portions of the LC around bregma $-5.78 \mathrm{~mm}$ and are positioned close to the dorsal surface of the tissue (Fig. $1 A$ ). When moving from caudal to rostral through the LC, the modules spread laterally and ventrally, forming numerous discrete clusters (Fig. 1B). From section to section, discrete modules appear to fuse together to form larger, continuous areas of stained tissue (Fig. 1C). In the rostralmost sections of the LC, the modules curve and project perpendicularly toward the midline (Fig. $1 D, E$ ). At approximately bregma $-4.855 \mathrm{~mm}$, the modules are no longer discernible. The fusion and segregation of discrete modules creates a lattice-like three-dimensional architecture when the modular network is viewed from a lateral perspective (Fig. $1 F$ ).

To determine whether neurochemical modularity in the LC is present before the onset of hearing, we examined the LC of mice at postnatal day 8 (P8), which precedes hearing onset (Song et al., 2006). These sections were stained for GAD-67, PV, and CO (Fig. $1 G-I)$. All three markers clearly show the presence of modules at this stage in development. In comparison to adult tissue stained for the same markers, however, the staining intensity of modules in P8 animals appears diminished (for comparison, see Fig. 2).

\section{Different markers stain the same network of modules}

Though multiple markers delineate modularity in the LC, it is not known if a single network of modules exists, or if multiple networks exist, each with their own neurochemical signature. To answer this question, double immunostaining for GAD-67 and $\mathrm{PV}$ was done and revealed that the two markers stain identical regions of the LC (Fig. $2 A, B$ ). The content of the labeled material differs, however; GAD-67 predominately labels dense clusters of puncta (Fig. $2 A$, inset), while PV stains cell bodies and modular neuropil (Fig. $2 B$, inset). For $\mathrm{CO}$, AChE, and NADPH-d, double immunostaining was not feasible since these markers are typically stained with precipitate-based protocols; therefore, directly adjacent tissue sections were used. Comparison of GAD-67 and CO labeling in the LC in adjacent sections shows that these markers also stain the same network of modules (Fig. 2C,D). The same is true of GAD-67 and NADPH-d labeling in adjacent tissue sections (Fig. 2E,F). Modules stained with NADPH-d and AChE in adjacent sections also colocalize, suggesting that all of these markers label a single modular network in the LC (Fig. 2G,H).

\section{Auditory inputs interdigitate with GAD-67 modules}

To determine whether the termination patterns of inputs from the auditory cortex are spatially correlated with the distribution of modules in the LC, anterograde tracers were injected into the auditory cortex of three animals, and IC tissue sections were processed for GAD-67 immunohistochemistry. For case AUD-d/p/v, BDA was pressure injected into the auditory cortex, producing a large injection site that covered the dorsal, primary, and ventral 


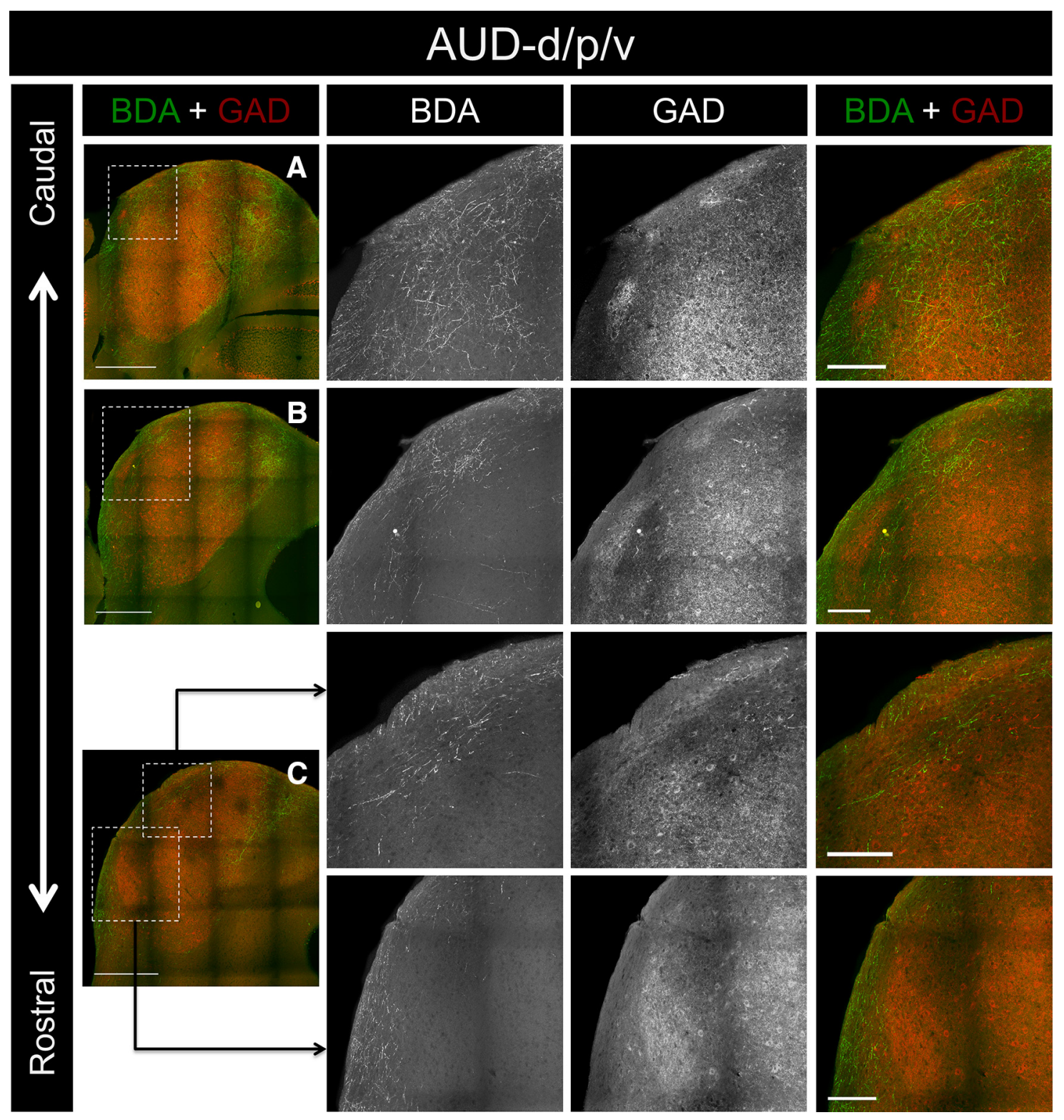

Figure 4. Inputs to the $\mathrm{LC}$ from case AUD-d/p/v. A, Low-power overlay image of BDA labeling and GAD-67 immunostaining in a caudal section of the IC. The ROI (outlined box) corresponds to the location of the $20 \times B D A, G A D-67$, and overlay images shown to the right. $B, B D A$ labeling and GAD-67 immunostaining in a midrostrocaudal section of the IC. C, BDA labeling and GAD-67 immunostaining in a rostral section of the IC. For $20 \times$ images in $A-C$, note the complementarity of the BDA and GAD-67 labeling. Scale bars: low-power images, $500 \mu \mathrm{m} ; 20 \times$ images, $150 \mu \mathrm{m}$.

regions of this structure (Fig. $3 A$ ). This injection site produced labeling throughout the rostrocaudal extent of the LC (Figs. $4 A-C, 5 A-C)$. In caudal regions of the LC, BDA-labeled axons and terminals were found densely and evenly dispersed in layer 3 , while the labeling in layer 1 consisted predominately of axonal fibers forming the brachium of the inferior colliculus (Figs. $4 A$, $5 A$ ). In layer 2 , however, regions of dense axonal and terminal labeling were interspersed with patches largely devoid of BDA-labeled material (Figs. $4 A, 5 A$ ). When compared with the GAD-67 labeling in the same tissue sections, these empty patches corresponded with the location of the GAD-67-stained neurochemical modules (Figs. 4A, 5A). In tissue sections located midway through the rostrocaudal axis of the LC, the same pattern of labeling was seen for layers 1 and 3 , as was evident in more caudal sections (Figs. 4B, 5B). In layer two, the BDA-rich areas became progressively smaller when moving rostrally through the tissue, while the empty patches and the corresponding GAD-67 mod- ules became larger (Figs. 4B, 5B). The overall density of BDAlabeled material decreased in the rostralmost sections of the LC, with far fewer labeled terminals and axons in layer 2 and 3. However, the same interdigitating pattern of GAD-67 modules and BDA labeling was evident in layer 2 (Figs. $4 C, 5 C$ ).

For case AUD-p, BDA was iontophoretically injected, resulting in a small injection site confined to the primary region of the auditory cortex (Fig. 3B). Despite the focal nature of the injection site, heavy BDA labeling was seen in the LC, and the pattern of axonal and terminal labeling throughout all layers of the LC was very similar to that in case AUD-d/p/v (Fig. $5 A-C$ vs $D-F$ ). Specifically, the same patches of sparse BDA labeling were seen in layer 2, and these regions corresponded with the locations of the GAD-67 modules (Fig. 5D-F).

To determine whether this interdigitating pattern of auditory corticocollicular fibers and modules is seen with multiple tracers, AAV5 was pressure injected into the dorsal and primary regions 


\section{Auditory Cortex Injections}

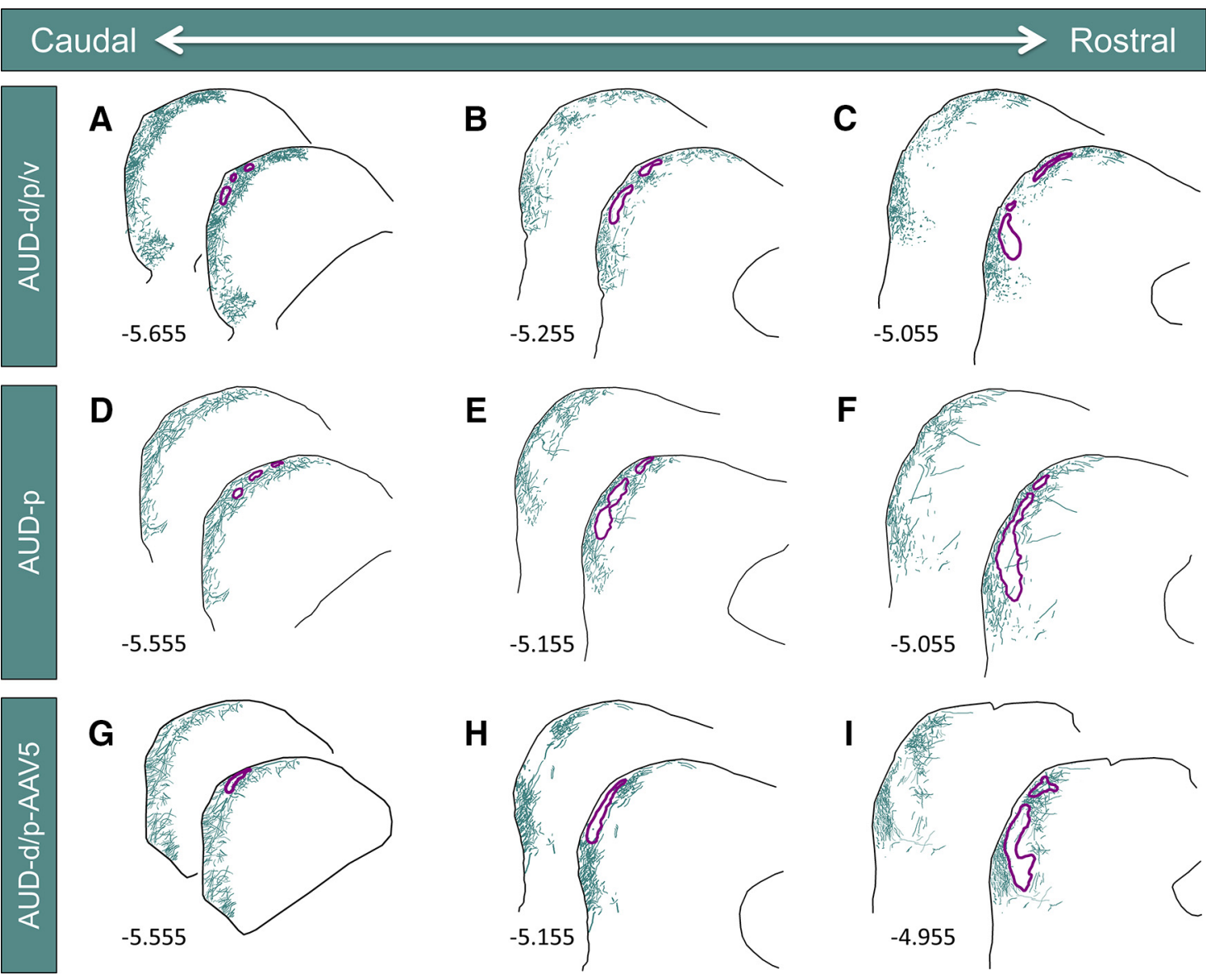

Figure 5. Inputs to the LC from the auditory cortex. A-C, Neurolucida reconstructions at three rostrocaudal levels of the LC from case AUD-d/p/v (photographs shown in Fig. 4). Labeled axons and terminals are shown in teal, while the outlines of the GAD-67 modules are shown in purple. Numbers in the lower left corners represent the rostrocaudal distance of the tissue section from bregma. $D, E$, Neurolucida reconstructions at three rostrocaudal levels of the LC from case AUD-p. G-I, Neurolucida reconstructions at three rostrocaudal levels of the LC from case AUD-d/p-AAV5. For all, note the interdigitation of BDA-rich and BDA-void areas in layer 2, corresponding to the location of the GAD-67 modules.

of the auditory cortex (case AUD-d/p-AAV5; Fig. 3C). In caudal and midlevel sections of the LC, interdigitation of the GAD-67 modules and labeled fibers was apparent (Fig. $5 G, H$ ). In more rostral sections, this modularity remained evident in the ventral half the LC, but became less conspicuous dorsally (Fig. 5I).

Previous studies have shown that the distribution of corticocollicular fibers mimics the topography of intracollicular projections (Saldaña and Merchań, 1992; Saldaña et al., 1996). To determine whether the intracollicular projections to the LC also interdigitate with the GAD-67 modules, BDA was iontophoretically injected into the CNIC of two different animals. For case CNIC-v, the injection site was centered near the ventral border between the CNIC and the LC (Fig. 3D). This injection site produced heavy labeling in all three layers in the ventral half the LC (Figs. 6A-D, 7A-D). Only sparse labeling was seen in the dorsal half of the LC, and this labeling was confined primarily to layer 3 . Throughout the rostrocaudal extent of the LC, the termination patterns of intracollicular projections were strikingly complementary to the distribution of GAD-67 modules (Figs. $6 A-D, 7 A-D)$.

This injection site also labeled commissural fibers projecting to the contralateral LC. In caudal and midlevel regions of the contralateral LC, thinly dispersed fibers were found in layer 2 and
3, predominately outside of the GAD-67 modules (Fig. $7 E, F$ ). The labeling intensified in more rostral sections of the contralateral LC, revealing complementarity with the GAD-67 modules (Fig. $7 G$ ).

For case CNIC-d, BDA was injected in the dorsal CNIC, with some spillover into the LC (Fig. 3E). In contrast to case CNIC-v, this injection site produced heavy labeling in all three layers of the dorsal half of the LC and sparser labeling in the ventral half of the LC (Fig. $7 H-J)$. The BDA-labeled material was most densely packed in caudal regions of the LC, where modularity in layer 2 was least evident (Fig. $7 H$ ). In more rostral sections, layer 2 was characterized by interlocking clusters of BDA-rich and BDA-void regions, with the $\mathrm{BDA}$-void regions corresponding to the location of GAD-67 modules (Fig. 7I,J). Compared to case CNIC-v, commissural labeling in case CNIC-d was much less prominent and was largely restricted to the contralateral CNIC (data not shown).

\section{Somatosensory inputs project into the modules}

To determine whether the termination patterns of somatosensory corticocollicular inputs to the LC are also correlated with the distribution of neurochemical modules, several injections were made into various subregions of the somatosensory cortex. For 


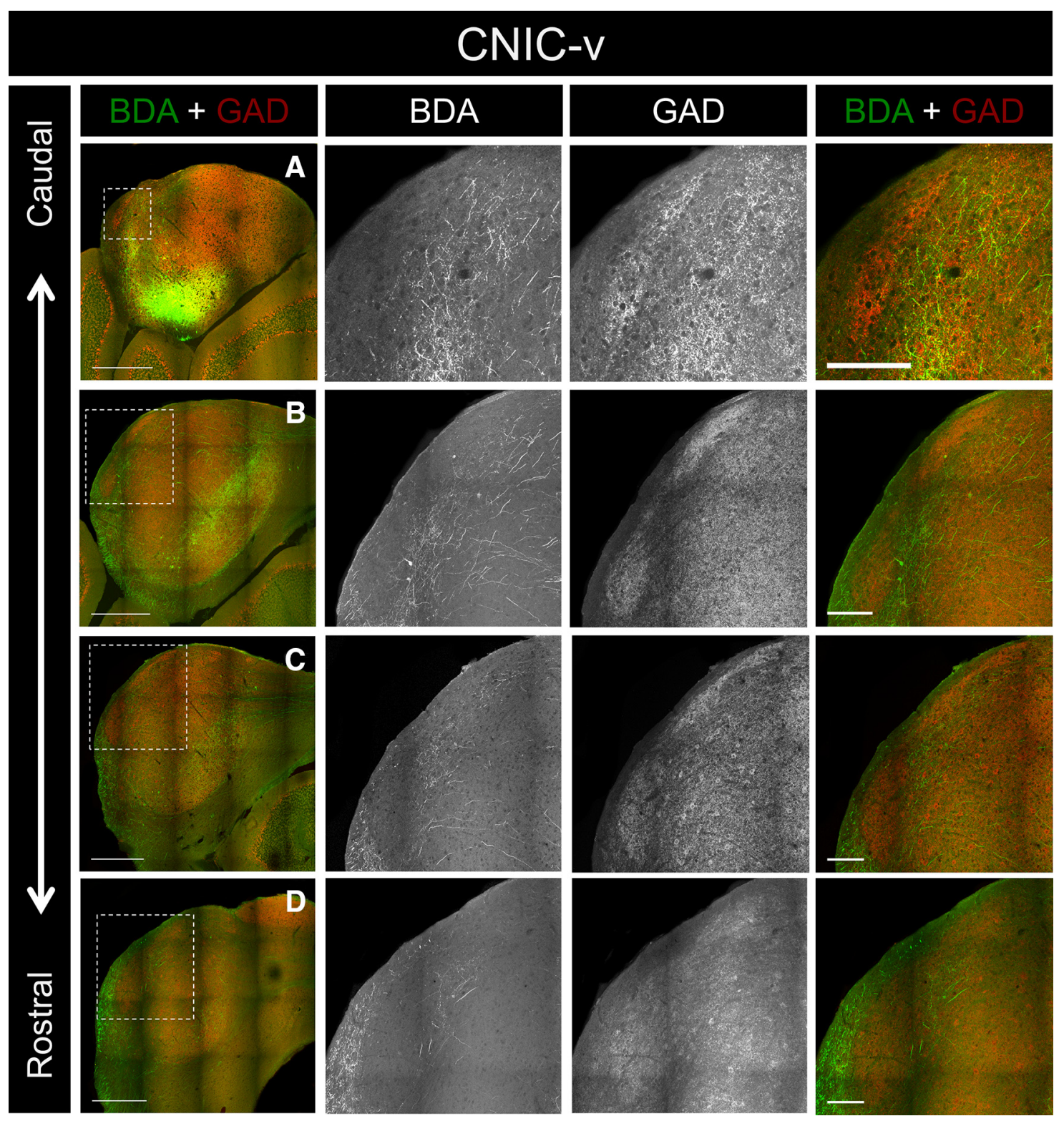

Figure 6. Inputs to the LC from case CNIC-v. A, Low-power overlay image of BDA labeling and GAD-67 immunostaining in a caudal section of the IC. The ROI (outlined box) corresponds to the location of the $20 \times$ BDA, GAD-67, and overlay images shown to the right. B, BDA labeling and GAD-67 immunostaining in another caudal section of the IC. C, BDA labeling and GAD-67 immunostaining in a midrostrocaudal section of the IC. D, BDA labeling and GAD-67 immunostaining in a rostral section of the IC. For $20 \times$ images in $A-D$, note the complementarity of the BDA and GAD-67 labeling. Scale bars: low-power images, $500 \mu \mathrm{m} ; 20 \times$ images, $150 \mu \mathrm{m}$.

case SSp-tr, the injection site was centered in the trunk region of the primary somatosensory cortex (Fig. $3 F$ ). This injection site produced labeling exclusively in the rostral half of the LC; no BDA-labeled terminals were found caudal to bregma $-5.255 \mathrm{~mm}$ (Figs. 8A, 9A). Labeled axons and terminals were found predominately in layer 2 , specifically in regions corresponding to the location of the GAD-67 modules (Figs. $8 A-C, 9 A-C$ ). In some sections, individual axons were found that branched and innervated multiple distinct modules (Figs. 8C, 9C).

The injection site for case SSp-tr/PTLp also filled the trunk region of the primary somatosensory cortex, with some caudal spillover into the posterior parietal association areas (Fig. $3 G$ ). Similar to case SSp-tr, the resulting LC label was restricted to the rostral half of the LC, with no labeled terminals found caudal to bregma $-5.38 \mathrm{~mm}$. The innervated areas of the LC correlated strikingly with the location of the GAD-67 modules (Fig. 9D-F).
For case SSp-tr/MOp, BDA was injected in more rostral regions of the trunk area (with spillover into the primary motor areas) than in the previously mentioned cases (Fig. $3 H$ ). The resulting label in the $\mathrm{LC}$ was also restricted to more rostral sections, with no terminal labeling found caudal to bregma $-5.055 \mathrm{~mm}$ (Fig. 9G). Similar to the other cases, the labeled terminals and axons were found to project primarily into the GAD-67 modules. The most rostral injection site, case SSp-ul/ SSp-ll, was centered between the upper limb and lower limb regions of the primary somatosensory cortex (Fig. 3I). Interestingly, this injection site only gave rise to labeling in the rostralmost sections of the LC, corresponding to bregma -4.855 (Fig. 9I). The fact that more rostral injection sites within the somatosensory cortex gave rise to progressively more rostral labeling in the LC is suggestive of a topographic relationship. 


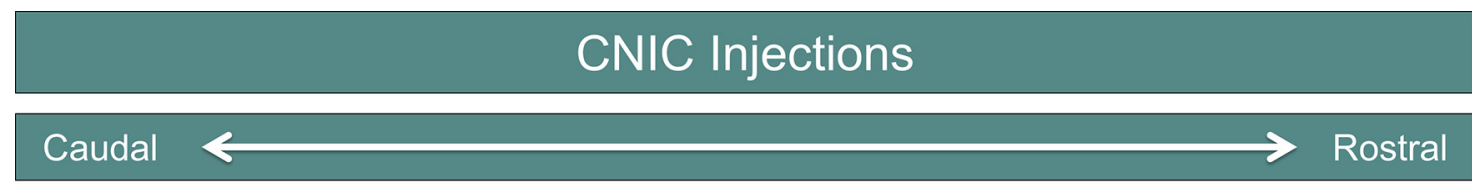

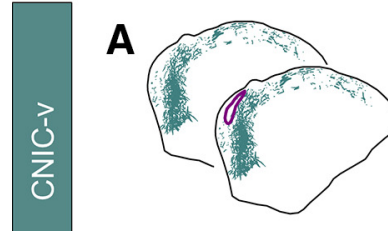

$-5.78$
B

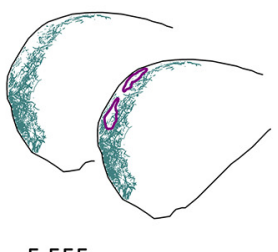

$-5.555$
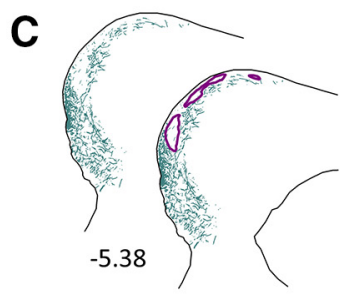

$\mathbf{F}$

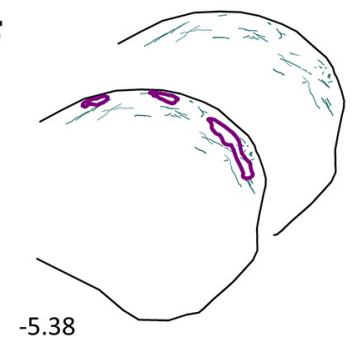

I

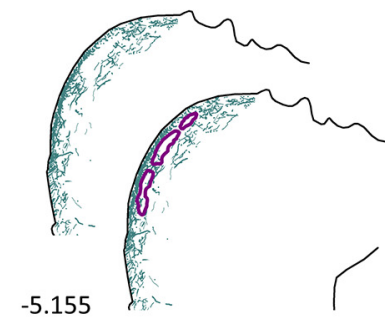

D

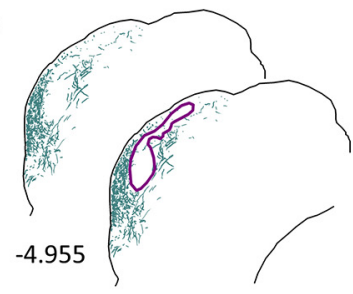

G
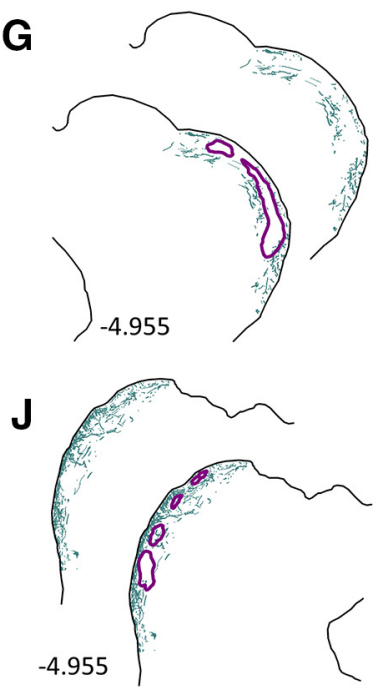

Figure 7. Inputs to the LC from the CNIC. $A-D$, Neurolucida reconstructions at four rostrocaudal levels of the LC from case CNIC-v (photographs shown in Fig. 6). Labeled axons and terminals are shown in teal, while the outlines of the GAD-67 modules are shown in purple. Numbers in the lower left corners represent the rostrocaudal distance of the tissue section from bregma. $\boldsymbol{E}-\boldsymbol{G}$, Neurolucida reconstructions at three rostrocaudal levels of the contralateral LC from case CNIC-v showing the distribution of commissural projections. $\boldsymbol{H}-\boldsymbol{J}$, Neurolucida reconstructions at three rostrocaudal levels of the LC from case CNIC-d. For all, note the complementarity of the BDA and GAD-67 labeling.

To determine whether somatosensory brainstem inputs also project into the modules, BDA was iontophoretically injected into the dorsal column nuclei of one animal (Fig. 3J). Though the injection site was relatively small, it produced dense labeling in layer 2 of the LC (Figs. 9J-M, 10A-D). Unlike the projections from the somatosensory cortex, the resulting label was found throughout virtually the entire rostrocaudal extent of the LC (Fig. $9 J-M, 10 A-D)$. The pattern of terminal labeling was virtually identical to the distribution of GAD-67 modules throughout the LC. Interestingly, BDA-labeled axons and terminals en passant were also found in the CNIC (Fig. 10 B, C, arrowheads).

\section{Discussion}

The results of the present study indicate that the mouse LC contains a single network of neurochemical modules that stain positively for GAD-67, PV, NADPH-d, AChE, and CO. Furthermore, the data presented here suggest that neurochemical modularity in the LC predicts connectional modularity; somatosensory inputs terminate within the modules, while auditory inputs are found predominately in extramodular regions of the LC (Fig. 11).

\section{Contradictions with previous reports}

Chernock et al. (2004) reported previously that modules positive for GAD-67, PV, AChE, CO, and NADPH-d are present in the rat, but are absent in mouse, squirrel, cat, bat, macaque monkey, and barn owl. However, images of mouse tissue from other sources depict modular staining patterns in the LC for GAD-67, AChE, NADPH-d, and CO (Gonzalez-Lima and Cada, 1994; Paxinos and Franklin, 2004; Ono et al., 2005; Stebbings et al., 2014; Choy Buentello et al., 2015). In addition, images of stained tissue from other species reveal modules in the LC of the gerbil and the rhesus macaque (Paxinos et al., 1999; Cant and Benson, 2005). Though not always commented on in the text of these reports, these findings suggest that neurochemical modularity is seen in the LC in species ranging from mouse to primate.

\section{Origin of neurochemical modules}

We find that neurochemical modules are present in the LC as early as postnatal day 8 , indicating that they form before the onset of hearing. Given that modular areas are targeted by somatosensory structures, it is possible that somatosensory input early in development helps drive their formation. Previous studies have found that discrete clusters of the axon guidance molecules Eph receptor A4 and ephrin-B2 are present in the LC of the rat and mouse, respectively, throughout the first postnatal week, and gradually fade before the onset of hearing (Gabriele et al., 2011). Given their patchy appearance, it is probable that these clusters colocalize with the neurochemical modules in the LC, and may play a role in the precise patterning of inputs to this region.

The sources of modular neuropil in the LC remain unknown. Given that the modules contain both GAD-67-positive cells and dense GAD-67-labeled puncta, it is possible that GABAergic cells within the 


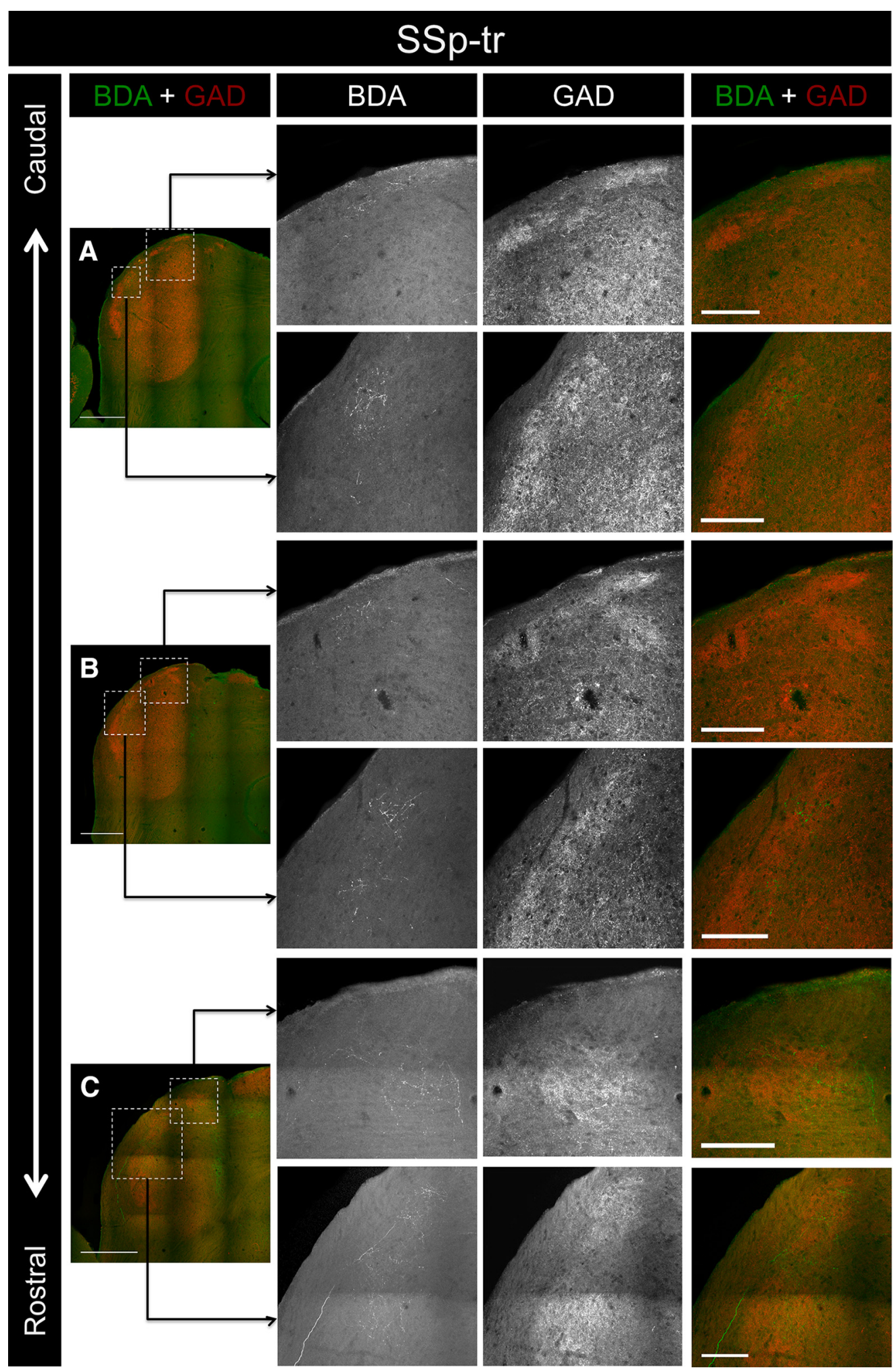

Figure 8. Inputs to the LC from case SSp-tr. A, Low-power overlay image of the BDA labeling and GAD-67 immunostaining in the caudalmost section of the IC containing labeled terminals. The ROls (outlined boxes) correspond to the locations of the $20 \times B D A, G A D-67$, and overlay images shown to the right. $B$, BDA labeling and GAD-67 immunostaining in a more rostral section of the IC. C, BDA labeling and GAD-67 immunostaining in a rostral section of the IC. For 20X images in $A-C$, note that the BDA label corresponds with the location of the GAD-67 modules. Scale bars: low-power images, $500 \mu \mathrm{m} ; 20 \times$ images, $150 \mu \mathrm{m}$.

modules give rise to the labeled neuropil and terminals, or that extrinsic GABAergic inputs, such as the substantia nigra pars lateralis, also contribute (Coleman and Clerici, 1987). The modules also stain for AChE, indicating that they receive cholinergic inputs. The major sources of acetylcholine in the IC come from the laterodorsal tegmental nucleus and the pedunculopontine tegmental nucleus (Motts and Schofield, 2009). Interestingly, these same nuclei have been found to give rise to the AChE modules in the SC (Wallace and Fredens, 1988; Hall et al., 1989). 


\section{Somatosensory Injections}

Caudal
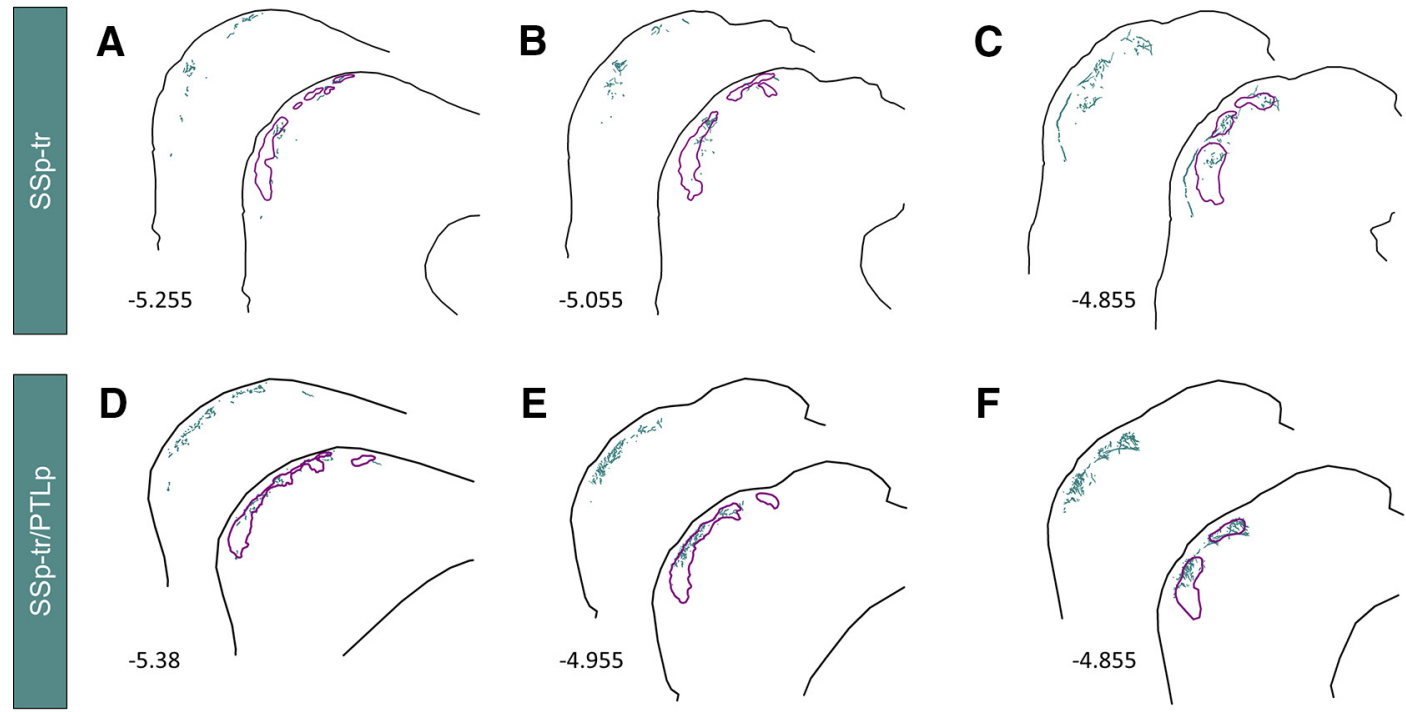

$\mathbf{F}$
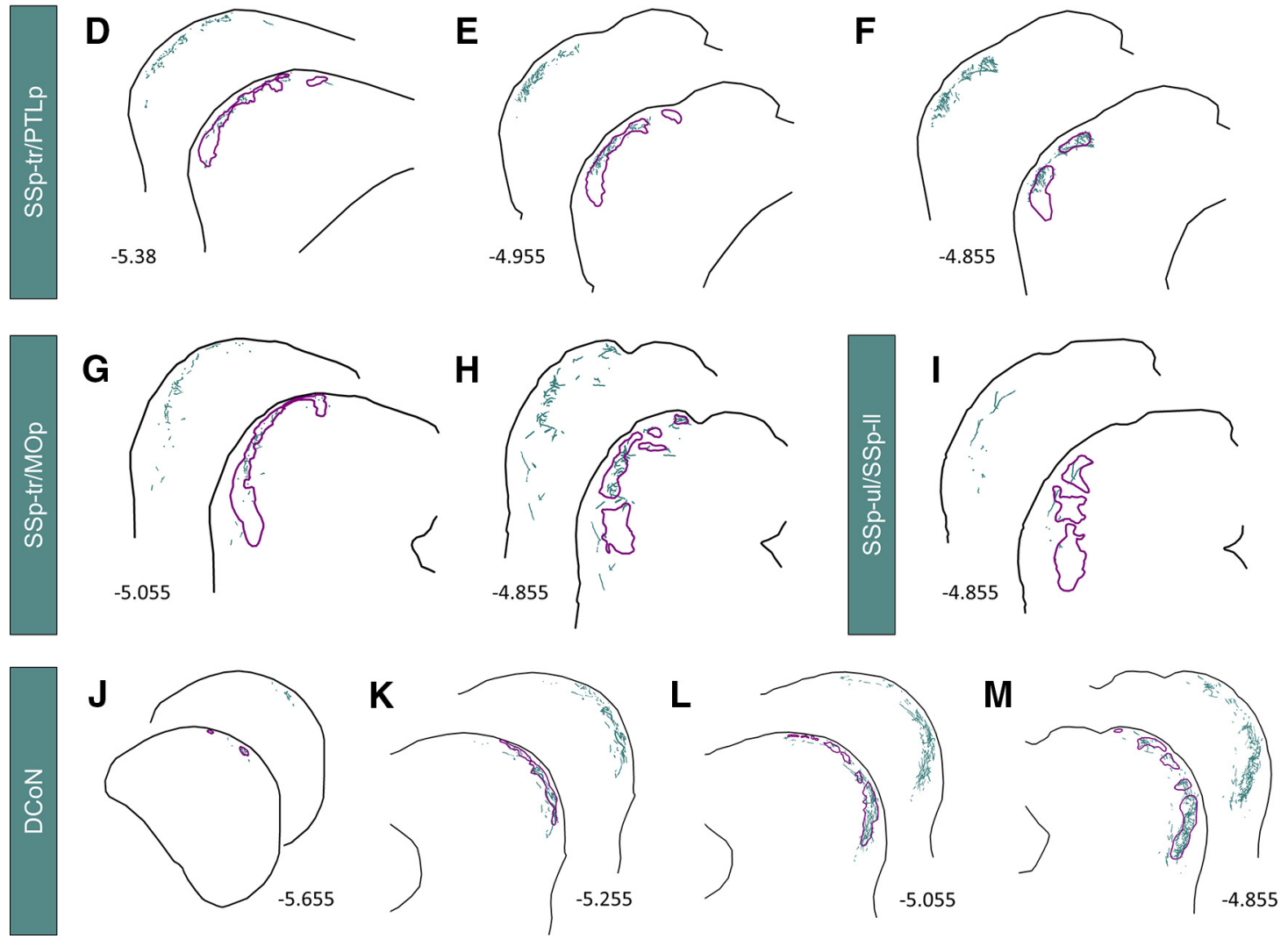

Figure 9. Somatosensory inputs to the LC. $A-C$, Neurolucida reconstructions at three rostrocaudal levels of the LC from case SSp-tr (photographs shown in Fig. 8). Labeled axons and terminals are shown in teal, while the outlines of the GAD-67 modules are shown in purple. Numbers in the lower left corners represent the rostrocaudal distance of the tissue section from bregma. $\boldsymbol{D}-\boldsymbol{F}$, Neurolucida reconstructions at three rostrocaudal levels of the LC from case SSp-tr/PTLp. G, $\boldsymbol{H}$, Neurolucida reconstructions at two rostrocaudal levels of the LC from case SSp-tr/MOp. I, Neurolucida reconstruction of the exclusively rostral labeling in the LC from case SSp-ul/SSp-II. J-M, Neurolucida reconstructions at four rostrocaudal levels of the LC from case DCoN (photographs shown in Fig. 10). For all, note the similar distributions of BDA and GAD-67 labeling.

\section{Connectional modularity of the LC}

We demonstrate here that the termination patterns of at least four of the major inputs to the LC are related to its underlying neurochemical modularity. Another major source of somatosensory input to the LC arises from the spinal trigeminal nucleus. Previous studies that have plotted the terminals in the $\mathrm{LC}$ arising from the spinal trigeminal nucleus have shown that they terminate in distinctive clusters that resemble the input patterns from the dorsal column nuclei and somatosensory cortex (Wise and Jones, 1977; Wiberg and Blomqvist, 1984; Wiberg et al., 1987). Input to the LC from auditory brainstem structures, such as the cochlear nucleus and the lateral lemniscus, is largely restricted to layer 3 , suggesting that this input is extramodular (Coleman and Clerici, 1987; GonzálezHernández et al., 1996; Gabriele et al., 2000; Malmierca et al., 2005; Loftus et al., 2008). In a dual anterograde tract-tracing study, Zhou and Shore (2006) labeled afferents to the LC from the cochlear nucleus and spinal trigeminal nucleus in the guinea pig. They observed convergence of these inputs at the ventrolateral border region of the IC, indicating a potential anatomical substrate for multisensory integration. It is worth noting, however, that convergence of these inputs was absent throughout the majority of the LC, and the termination patterns from both of these structures appeared to form distinct clusters (Zhou and Shore, 2006). While it is unknown if neurochemical modules exist in the guinea pig, it is possible that 


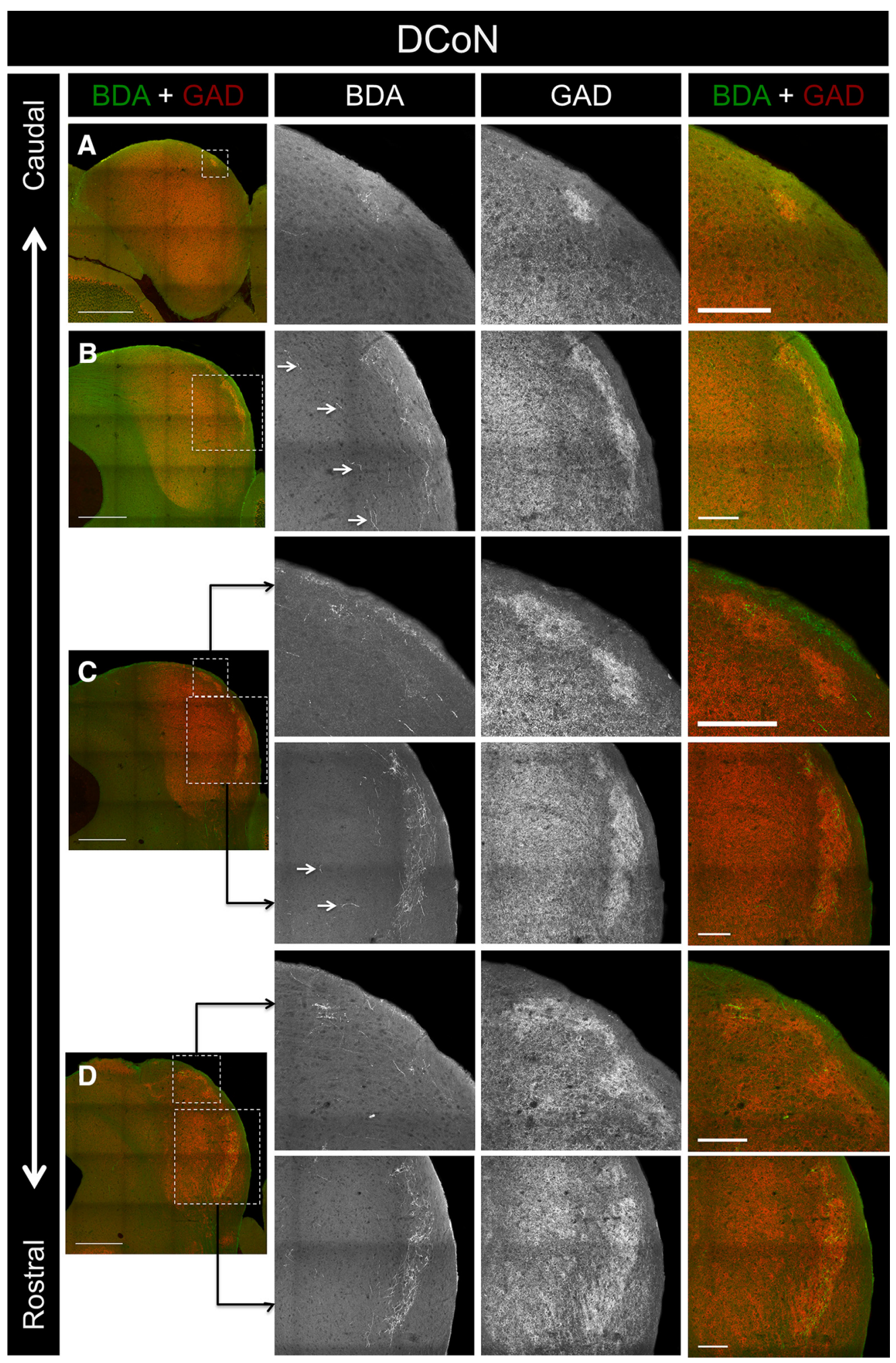

Figure 10. Inputs to the LC from case DCON. A, Low-power overlay image of BDA labeling and GAD-67 immunostaining in a caudal section of the IC. The ROI (outlined box) corresponds to the location of the $20 \times B D A, G A D-67$, and overlay images shown to the right. $B, B D A$ labeling and GAD-67 immunostaining in a midrostrocaudal section of the IC. Arrowheads indicate the presence of labeled axons and terminals in the CNIC. C, BDA labeling and GAD-67 immunostaining in another midrostrocaudal section of the IC. Arrowheads indicate the presence of labeled axons and terminals in the CNIC. D, BDA labeling and GAD-67 immunostaining in a rostral section of the IC. For 20× images in $\boldsymbol{A}-\boldsymbol{D}$, note the similar patterns of the BDA and GAD-67 labeling. Scale bars: low-power images, $500 \mu \mathrm{m} ; 20 \times$ images, $150 \mu \mathrm{m}$.

the inputs to the LC in this species exhibit the type of connectional modularity seen in the present study.

The LC also receives input from other brain regions, including the deep layers of the SC, the visual cortex, substantia nigra, mid- brain central gray, and hypothalamus (Coleman and Clerici, 1987). It is unknown how these projections relate to the organization of the connections studied here and whether or not they have a topographic relationship with the modules. 


\section{Similarity to organization of the deep layers of the SC}

The type of connectional and neurochemical modularity described here has been established as an organizational feature of the deep layers of the SC. Similar to the LC, the deep layers of the SC are the target of both ascending and descending inputs from multiple sensory and motor areas (Sparks and Hartwich-Young, 1989), which also terminate in discrete clusters (Mana and Chevalier, 2001b). Furthermore, the distribution of chemical markers within the deep layers has been described as modular or "latticelike" (Chevalier and Mana, 2000). Multiple neurochemical lattices exist within the SC (Illing, 1996); this is an interesting point of divergence from what we have observed in the present study, with all of the modular markers colocalizing with each other within the LC. Particular inputs to the deep layers of the SC either overlay or interdigitate with modules for a specific marker; for example, afferents from the substantia nigra terminate within the acetylcholinesterase lattice (Mana and Chevalier, 2001a).

The fact that the LC and the SC share common anatomical features could indicate that they are related in their functional roles as well. The SC is known to be involved in a number of visuomotor functions, including visual orienting and approach, escape, and defense behaviors (Redgrave et al., 1993). Previous investigators have hypothesized that the LC functions as an acousticomotor nucleus, given that it projects to the SC and the cerebellum (Huffman and Henson, 1990). Cells in both the superior colliculus and the LC have been shown to exhibit stimulus-specific adaptation, indicating that both of these structures may be involved in the detection of unexpected stimuli in the environment (Gutfreund, 2012; Ayala and Malmierca, 2012, 2015).

Other brain regions have also been revealed to have neurochemical and connectional modularity that ultimately proved important in understanding their function. Within the auditory system, the ventral nucleus of the lateral lemniscus contains discontinuous patches of labeled afferents and efferents that are thought to represent interdigitating frequencyband components (Malmierca et al., 1998). The striatum is organized into compartments, striosomes and matrix, which, similar to the LC, have neurochemical and connectional segregation, and also play distinct roles in motor physiology (Graybiel and Ragsdale, 1978; Kincaid and Wilson, 1996; Fujiyama et al., 2015). Similar neurochemical, connectional, and functional segregation is seen in the patch/interpatch system of the visual cortex (Hendrickson et al., 1981; Livingstone and Hubel, 1988; Sincich and Horton, 2005). Whether the modularity uncovered in the current study ultimately leads to a greater understanding of the functional pathways linking the $\mathrm{LC}$ to other regions remains to be seen.

\section{Functional implications for multisensory integration}

The LC has long been implicated in multisensory functions. Early recordings from the cat $\mathrm{LC}$ uncovered single units that respond to both auditory and somatosensory stimuli (Aitkin et al., 1978; 1981). Other studies that have examined the effect of spinal trigeminal or dorsal column stimulation on responses to sound in the LC have found that the majority of units respond bimodally (Aitkin et al., 1978; Jain and Shore, 2006). If, as suggested by the present study, auditory and somatosensory pathways are indeed largely anatomically segregated within the LC, the presence of such multisensory influence would require either integration among the two senses in a lower structure that projects to the LC or interactions among modular and extramodular areas within the LC. The cochlear nucleus is one such site of multisensory integration within the auditory pathway (Basura et al., 2012), and it projects directly to the LC (Wu et al., 2015). It is possible that information from the auditory and somatosensory systems converges here and is reflected in recordings from IC units. As yet, there is no direct evidence for interactions between modular and extramodular areas of the LC. However, the cells in this region are known to have axon collaterals that branch extensively throughout the LC, and their dendritic fields can span up to $800 \mu \mathrm{m}$ in diameter, indicating that such communication between these areas is possible (Smith, 1992; Malmierca et al., 2011).

Given the evidence for the role of the LC in multisensory integration, it is peculiar that the somatosensory and auditory inputs to the LC studied here are largely segregated. One potential advantage of such an arrangement could be to compare ascending and descending information from within a single modality before integrating across modalities. If so, this could indicate that the modules function as unimodal integrators of ascending and descending somatosensory information, while the nearby extramodular areas perform a similar bottom-up/top-down integrative function for the auditory system. 


\section{References}

Adams JC (1980) Crossed and descending projections to the inferior colliculus. Neurosci Let 19:1-5. CrossRef

Aitkin LM, Dickhaus H, Schult W, Zimmermann M (1978) External nucleus of inferior colliculus: auditory and spinal somatosensory merents and their interactions. J Neurophysiol 41:837-847 Medline

Aitkin LM, Kenyon CE, Philpott P (1981) The representation of the auditory and somatosensory systems in the external nucleus of the cat inferior colliculus. J Comp Neurol 196:25-40. CrossRef Medline

Ayala YA, Malmierca MS (2012) Stimulus-specific adaptation and deviance detection in the inferior colliculus. Front Neural Circuits 6:89. Medline

Ayala YA, Malmierca MS (2015) Cholinergic modulation of stimulusspecific adaptation in the inferior colliculus. J Neurosci 35:12261-12272. CrossRef Medline

Basura GJ, Koehler SD, Shore SE (2012) Multi-sensory integration in brainstem and auditory cortex. Brain Res 1485:95-107. CrossRef Medline

Björkeland M, Boivie J (1984) An anatomical study of the projections from the dorsal column nuclei to the midbrain in cat. Anat Embryol 170:2943. CrossRef Medline

Cant NB, Benson CG (2005) An atlas of the inferior colliculus of the gerbil in three dimensions. Hear Res 206:12-27. CrossRef Medline

Chernock ML, Larue DT, Winer JA (2004) A periodic network of neurochemical modules in the inferior colliculus. Hear Res 188:12-20. CrossRef Medline

Chevalier G, Mana S (2000) Honeycomb-like structure of the intermediate layers of the rat superior colliculus, with additional observations in several other mammals: AChE patterning. J Comp Neurol 419:137153. CrossRef Medline

Choy Buentello D, Bishop DC, Oliver DL (2015) Differential distribution of GABA and glycine terminals in the inferior colliculus of rat and mouse. J Comp Neurol 523:2683-2697. CrossRef Medline

Coleman JR, Clerici WJ (1987) Sources of projections to subdivisions of the inferior colliculus in the rat. J Comp Neurol 262:215-226. CrossRef Medline

Cooper MH, Young PA (1976) Cortical projections to the inferior colliculus of the cat. Exp Neurol 51:488-502. CrossRef Medline

Cramer KS, Gabriele ML (2014) Axon guidance in the auditory system: multiple functions of Eph receptors. Neuroscience 277:152-162. CrossRef Medline

Faye-Lund H (1985) The neocortical projection to the inferior colliculus in the albino rat. Anat Embryol 173:53-70. CrossRef Medline

Faye-Lund H, Osen KK (1985) Anatomy of the inferior colliculus in rat. Anat Embryol 171:1-20. CrossRef Medline

Fujiyama F, Takahashi S, Karube F (2015) Morphological elucidation of basal ganglia circuits contributing reward prediction. Front Neurosci 9:6. Medline

Gabriele ML, Brunso-Bechtold JK, Henkel CK (2000) Development of afferent patterns in the inferior colliculus of the rat: projection from the dorsal nucleus of the lateral lemniscus. J Comp Neurol 416:368-382. CrossRef Medline

Gabriele ML, Brubaker DQ, Chamberlain KA, Kross KM, Simpson NS, Kavianpour SM (2011) EphA4 and ephrin-B2 expression patterns during inferior colliculus projection shaping prior to experience. Dev Neurobiol 71:182-199. CrossRef Medline

Goldowitz D (2010) Allen reference atlas. A digital color brain atlas of the C57BL/6J male mouse-by HW Dong. Genes Brain Behav 9:128. CrossRef

González-Hernández T, Mantolán-Sarmiento B, González-González B, Pérez-González H (1996) Sources of GABAergic input to the inferior colliculus of the rat. J Comp Neurol 372:309-326. CrossRef Medline

Gonzalez-Lima F, Cada A (1994) Cytochrome oxidase activity in the auditory system of the mouse: a qualitative and quantitative histochemical study. Neuroscience 63:559-578. CrossRef Medline

Graybiel AM, Ragsdale CW Jr (1978) Histochemically distinct compartments in the striatum of human, monkeys, and cat demonstrated by acetylthiocholinesterase staining. Proc Natl Acad Sci U S A 75:57235726. CrossRef Medline

Gutfreund Y (2012) Stimulus-specific adaptation, habituation and change detection in the gaze control system. Biol Cybern 106:657-668. CrossRef Medline

Hall WC, Fitzpatrick D, Klatt LL, Raczkowski D (1989) Cholinergic innervation of the superior colliculus in the cat. J Comp Neurol 287:495-514. CrossRef Medline

Hand PJ, Van Winkle T (1977) The efferent connections of the feline nucleus cuneatus. J Comp Neurol 171:83-109. CrossRef Medline
Hendrickson AE, Hunt SP, Wu JY (1981) Immunocytochemical localization of glutamic acid decarboxylase in monkey striate cortex. Nature 292: 605-607. CrossRef Medline

Huffman RF, Henson OW Jr (1990) The descending auditory pathway and acousticomotor systems: connections with the inferior colliculus. Brain Res Rev 15:295-323. CrossRef Medline

Illing RB (1996) The mosaic architecture of the superior colliculus. Prog Brain Res 112:17-34. CrossRef Medline

Ito T, Bishop DC, Oliver DL (2009) Two classes of GABAergic neurons in the inferior colliculus. J Neurosci 29:13860-13869. CrossRef Medline

Jain R, Shore S (2006) External inferior colliculus integrates trigeminal and acoustic information: unit responses to trigeminal nucleus and acoustic stimulation in the guinea pig. Neurosci Lett 395:71-75. CrossRef Medline

Jane JA, Schroeder DM (1971) A comparison of dorsal column nuclei and spinal afferents in the European hedgehog (Erinaceus europeaus). Exp Neurol 30:1-17. CrossRef Medline

Karnovsky MJ, Roots L (1964) A “direct-coloring” thiocholine method for cholinesterases. J Histochem Cytochem 12:219-221. CrossRef Medline

Kincaid AE, Wilson CJ (1996) Corticostriatal innervation of the patch and matrix in the rat neostriatum. J Comp Neurol 374:578-592. Medline

Li H, Mizuno N (1997) Single neurons in the spinal trigeminal and dorsal column nuclei project to both the cochlear nucleus and the inferior colliculus by way of axon collaterals: a fluorescent retrograde double-labeling study in the rat. Neurosci Res 29:135-142. CrossRef Medline

Ling C, Hendrickson ML, Kalil RE (2012) Resolving the detailed structure of cortical and thalamic neurons in the adult rat brain with refined biotinylated dextran amine labeling. PLoS One 7:e45886. CrossRef Medline

Livingstone M, Hubel D (1988) Segregation of form, color, movement, and depth: anatomy, physiology, and perception. Science 240:740-749. CrossRef Medline

Loftus WC, Malmierca MS, Bishop DC, Oliver DL (2008) The cytoarchitecture of the inferior colliculus revisited: a common organization of the lateral cortex in rat and cat. Neuroscience 154:196-205. CrossRef Medline

Malmierca MS, Leergaard TB, Bajo VM, Bjaalie JG, Merchán MA (1998) Anatomic evidence of a three-dimensional mosaic pattern of tonotopic organization in the ventral complex of the lateral lemniscus in cat. J Neurosci 18:10603-10618. Medline

Malmierca MS, Saint Marie RL, Merchan MA, Oliver DL (2005) Laminar inputs from dorsal cochlear nucleus and ventral cochlear nucleus to the central nucleus of the inferior colliculus: two patterns of convergence. Neuroscience 136:883-894. CrossRef Medline

Malmierca MS, Blackstad TW, Osen KK (2011) Computer-assisted 3-D reconstructions of Golgi-impregnated neurons in the cortical regions of the inferior colliculus of rat. Hear Res 274:13-26. CrossRef Medline

Mana S, Chevalier G (2001a) The fine organization of nigro-collicular channels with additional observations of their relationships with acetylcholinesterase in the rat. Neuroscience 106:357-374. CrossRef Medline

Mana S, Chevalier G (2001b) Honeycomb-like structure of the intermediate layers of the rat superior colliculus: afferent and efferent connections. Neuroscience 103:673-693. CrossRef Medline

Motts SD, Schofield BR (2009) Sources of cholinergic input to the inferior colliculus. Neuroscience 160:103-114. CrossRef Medline

Mugnaini E, Oertel WH (1985) An atlas of the distribution of GABAergic neurons and terminals in the rat CNS as revealed by GAD immunohistochemistry. In: Handbook of Chemical Neuroanatomy, Vol 4, pp 436-608. Amsterdam: Elsevier.

Ono M, Yanagawa Y, Koyano K (2005) GABAergic neurons in inferior colliculus of the GAD67-GFP knock-in mouse: electrophysiological and morphological properties. Neurosci Res 51:475-492. CrossRef Medline

Paloff AM, Usunoff KG (1991) Projections to the inferior colliculus from the dorsal column nuclei. An experimental electron microscopic study in the cat. J Hirnforschung 33:597-610. Medline

Paxinos G, Franklin KBJ (2004) The mouse brain in stereotaxic coordinates. San Diego: Gulf Professional.

Paxinos G, Huang X, Toga AW (1999) The rhesus monkey brain in stereotaxic coordinates. San Diego: Academic Press.

Redgrave P, Westby GW, Dean P (1993) Functional architecture of rodent superior colliculus: relevance of multiple output channels. Prog Brain Res 95:69-77. CrossRef Medline

Robards MJ (1979) Somatic neurons in the brainstem and neocortex projecting to the external nucleus of the inferior colliculus: an anatomical study in the opossum. J Comp Neurol 184:547-565. CrossRef Medline 
RoBards MJ, Watkins DW 3rd, Masterton RB (1976) An anatomical study of some somesthetic afferents to the intercollicular terminal zone of the midbrain of the opossum. J Comp Neurol 170:499-524. CrossRef Medline

Saldaña E, Merchán MA (1992) Intrinsic and commissural connections of the rat inferior colliculus. J Comp Neurol 319:417-437. CrossRef Medline

Saldaña E, Feliciano M, Mugnaini E (1996) Distribution of descending projections from primary auditory neocortex to inferior colliculus mimics the topography of intracollicular projections. J Comp Neurol 371:15-40. CrossRef Medline

Scherer-Singler U, Vincent SR, Kimura H, McGeer EG (1983) Demonstration of a unique population of neurons with NADPH-diaphorase histochemistry. J Neurosci Methods 9:229-234. CrossRef Medline

Schroeder DM, Jane JA (1971) Projection of dorsal column nuclei and spinal cord to brainstem and thalamus in the tree shrew, Tupaia glis. J Comp Neurol 142:309-350. CrossRef Medline

Schroeder DM, Jane JA (1976) The intercollicular area of the inferior colliculus. Brain Behav Evol 13:125-141. CrossRef Medline

Sincich LC, Horton JC (2005) The circuitry of V1 and V2: integration of color, form, and motion. Annu Rev Neurosci 28:303-326. CrossRef Medline

Smith PH (1992) Anatomy and physiology of multipolar cells in the rat inferior collicular cortex using the in vitro brain slice technique. J Neurosci 12:3700-3715. Medline

Song L, McGee J, Walsh EJ (2006) Frequency-and level-dependent changes in auditory brainstem responses (ABRS) in developing mice. J Acoust Soc Am 119:2242-2257. CrossRef Medline

Sparks DL, Hartwich-Young R (1989) The deep layers of the superior colliculus. Rev Oculomot Res 3:213-255. Medline

Stebbings KA, Lesicko AM, Llano DA (2014) The auditory corticocollicular system: molecular and circuit-level considerations. Hear Res 314:51-59. CrossRef Medline
Tokunaga A, Sugita S, Otani K (1983) Auditory and non-auditory subcortical afferents to the inferior colliculus in the rat. J Hirnforschung 25:461472. Medline

Wallace MN, Fredens K (1988) Origin of high acetylcholinesterase activity in the mouse superior colliculus. Exp Brain Res 72:335-346. Medline

Wiberg M, Blomqvist A (1984) The projection to the mesencephalon from the dorsal column nuclei. An anatomical study in the cat. Brain Res 311: 225-244. CrossRef Medline

Wiberg M, Westman J, Blomqvist A (1987) Somatosensory projection to the mesencephalon: an anatomical study in the monkey. J Comp Neurol 264:92-117. CrossRef Medline

Willard FH, Martin GF (1983) The auditory brainstem nuclei and some of their projections to the inferior colliculus in the North American opossum. Neuroscience 10:1203-1232. CrossRef Medline

Winer JA, Larue DT, Diehl JJ, Hefti BJ (1998) Auditory cortical projections to the cat inferior colliculus. J Comp Neurol 400:147-174. Medline

Wise SP, Jones EG (1977) Cells of origin and terminal distribution of descending projections of the rat somatic sensory cortex. J Comp Neurol 175:129-157. CrossRef Medline

Wong-Riley M (1979) Changes in the visual system of monocularly sutured or enucleated cats demonstrable with cytochrome oxidase histochemistry. Brain Res 171:11-28. CrossRef Medline

Wu C, Stefanescu RA, Martel DT, Shore SE (2015) Listening to another sense: somatosensory integration in the auditory system. Cell Tissue Res 361:233-250. Medline

Zhou J, Shore S (2006) Convergence of spinal trigeminal and cochlear nucleus projections in the inferior colliculus of the guinea pig. J Comp Neurol 495:100-112. CrossRef Medline 